\title{
Dialogue-Based Learning: A Framework for Inclusive Science Education and Applied Ethics
}

\section{OPEN ACCESS}

Edited by:

Meena M. Balgopal,

Colorado State University,

United States

Reviewed by:

Andrea Weinberg,

Arizona State University, United States Jennifer Neuwald,

Colorado State University,

United States

*Correspondence:

Michael R. Romano

heymichaelromano@gmail.com

Specialty section: This article was submitted to

Science and Environmental

Communication,

a section of the journal

Frontiers in Communication

Received: 28 June 2021 Accepted: 25 October 2021 Published: 19 November 2021

Citation:

Romano MR, Díaz-Almeyda E, Namdul $T$ and Lhundup Y (2021)

Dialogue-Based Learning: A

Framework for Inclusive Science

Education and Applied Ethics.

Front. Commun. 6:731839.

doi: $10.3389 /$ fcomm.2021.731839

\author{
Michael R. Romano ${ }^{1 *}$, Erika Díaz-Almeyda ${ }^{1}$, Tenzin Namdul ${ }^{2}$ and Yeshi Lhundup ${ }^{3}$ \\ ${ }^{1}$ Division of Natural Sciences, New College of Florida, Sarasota, FL, United States, ${ }^{2}$ Division of Epidemiology and Community \\ Health, University of Minnesota, Minneapolis, MN, United States, ${ }^{3}$ Drepung Loseling Monastery, Mundgod, India
}

Dialogue-based learning is an inclusive pedagogy that leverages epistemological pluralism in the classroom to enhance cross-cultural education, encourage critical thinking across modes of inquiry, and promote novel contributions in applied ethics. The framework emerged from the Buddhism-science dialogue and our experiences teaching science courses for Tibetan Buddhists in India through the Emory-Tibet Science Initiative. Buddhism and science are two modes of inquiry that emphasize critical inquiry and empiricism, yet navigating complementarities and points of friction is challenging. Our proposed framework aims to raise awareness of onto-epistemological assumptions to convert them from obstacles into assets in dialogue. In drawing attention to epistemological orientations, our framework demonstrates that receptivity to other ways of knowing fosters clarity in one's own views while creating space for new and enriching perspectives. In this article, we contextualize the Buddhism-science dialogue, explore the development of our dialogue-based learning framework, and demonstrate its application to a novel exchange about the COVID-19 pandemic. Broader aims of the framework include increasing scientific literacy and advancing transdisciplinary research.

Keywords: science education, inclusive pedagogy, applied ethics, cross-cultural education, epistemology, Tibetan Buddhism, dialogue, scientific literacy

\section{INTRODUCTION}

Is a jellyfish sentient? If all cells come from other cells, then where did the first cell come from? How do animals benefit when scientists experiment on them? How are mental states caused by brain states if scientists only refer to neural correlates? These are a few insights that Tibetan Buddhists raised in our classrooms in rural India as we taught science courses in the Emory-Tibet Science Initiative (ETSI). Tibetan monastic pedagogy centers on analytical debate (Perdue, 2014) and, despite having little science background, their aptitude in applying logic and discernment to newly acquired scientific concepts was humbling. ETSI encouraged us to recognize and articulate underlying ontoepistemological assumptions we carry as scientists that may not be shared by our students, and it inspired the development of a novel framework centered on epistemological pluralism as an inclusive pedagogy.

We propose dialogue-based learning as a framework for teaching science as a way of knowing by leveraging epistemological orientations to enhance diversity and inclusion, encourage critical thinking across modes of inquiry, and promote novel contributions in applied ethics. It is a two-way pedagogy, as dialogue encourages respect for modes of inquiry practiced by individuals within the classroom. Inevitably and beneficially, instructors become equal parts teacher and student. 
Broader aims of the framework include increasing scientific literacy and advancing transdisciplinary research.

In this article, we contextualize the Buddhism-science dialogue, explore the development of our framework, and demonstrate its application to a novel exchange about the COVID-19 pandemic.

\section{THE BUDDHISM-SCIENCE DIALOGUE}

What's past is prologue. Contextualizing the Buddhism-science dialogue establishes why dialogue is productive in cross-cultural education. Formal encounters between Buddhism and science began in the 19th century in the context of Western imperialism, raising questions about motivations and power dynamics (Jinpa, 2010; Vörös, 2016; Sheng, 2017). For example, Darwinian theory of evolution directly challenged Biblical creationism, a tension that reverberates today. Some Western scholars sought escape from Christianity's claim to authority (Samuel, 2014) and Buddhism aligned with naturalistic explanations (Cho, 2014). At the same time, Buddhists in Asia struggled for religious independence under imperialism by positioning Buddhism as science-compatible and on equal footing with Western philosophies (Samuel, 2014).

A major shift in the Buddhism-science dialogue began in the 1980s when formal meetings between the Dalai Lama and leading scientists and philosophers were first held by the Mind \& Life Institute (MLI) (Hasenkamp, 2019). MLI advanced the dialogue with its emphasis on Buddhism and science as equal partners. Collaborative research emerged in healthy qualities of mind and the effects of mental training on attention and emotion regulation (Jinpa, 2010). Francisco Varela, MLI co-founder, envisioned two broad contributions: 1) the integration of Buddhist first-person inquiry with scientific third-person inquiry; and 2) a rethinking of logic and epistemology across modes of inquiry (Hogendoorn, 2014).

In certain aspects, Varela's goals have not advanced. Buddhists and scientists frequently talk past each other, a pattern ascribed to discordant ontological assumptions (Samuel, 2014), with Euro-American onto-epistemologies dominating the dialogue (Cho, 2014). Cho argues that conflicts should also be considered from Buddhist perspectives, rather than reducing Buddhist views to objects of scientific inquiry. Buddhist concepts, Cho argues, are interpreted through Western frameworks, like karma reframed as Cartesian mind-body dualism rather than relative to its own Buddhist framework. Even agreement can end in misunderstandings. For example, Buddhism and science converge on the rejection of an independent, unitary self. But arising from onto-epistemological differences are divergences in: bases for rejection; how selfhood relates to other knowledge; and what, if any, ethical implications arise (Federman, 2011).

Two-way understanding can advance the Buddhism-science dialogue beyond the current plateau. ETSI aims to further Varela's goals by educating monastics to think critically across Buddhism and science (Desbordes \& Negi, 2013). ETSI began when the Dalai Lama invited Emory University to collaborate with the Library of Tibetan Works and Archives to develop a science curriculum for Tibetan Buddhists. Since 2006, dozens of scientists, translators, staff, and over one-thousand monastics have participated in a project similar in population to a small liberal arts college. Integrating science education represents the most significant change in 600-years for the Tibetan Buddhist curriculum (Kimelman, 2018), underscoring the Dalai Lama's confidence in the promise of novel and beneficial discoveries made by scholars trained in Buddhism and science. ETSI is a historic endeavor in the early years of what the Dalai Lama calls a 100-years project (Gray et al., 2020).

For more than 150-years, Buddhism-science compatibility claims have remained consistent while the meanings of Buddhism and science have changed considerably (Lopez, 2008). To avoid this trend, we clarify that in Buddhism we refer to Indo-Tibetan Buddhism, also known as the Nālandā tradition (Jinpa, 2010), by virtue of it being the population involved in ETSI, but not excluding other schools. To decolonize the term, we resist using "Western science" as ground for science. History of science is biased toward Eurocentrism (Wallingford, 2021), and cross-cultural science education often reflects Euro-American ontoepistemologies (Sonam, 2019). Indeed, centuries before the European Scientific Revolution, Buddhists originated advanced concepts in physics (atomic theory, relativity, multiple world systems) (Jinpa \& Lama, 2017), embryology (Wallingford, 2021), and microbiology (Hammerstrom, 2012). However, we also distinguish science from Buddhist science (Jinpa \& Lama, 2017, 2020). While both emphasize critical inquiry and empiricism (Lama, 2005), significant differences in onto-epistemological perspectives exist. Further, logic in the Nālandā tradition (Rogers, 2009) differs from Western logics (Mohanty, 1992). Consequently, we define science in terms of ontological commitments to physicalism and a mind-independent, objective reality knowable through replicable experimentation. This contrasts with the Buddhist view that mind is indispensable for knowing itself, with claims of an objective reality mediated by mind (Cho, 2012).

\section{DEVELOPING THE DIALOGUE-BASED LEARNING FRAMEWORK}

Science is not acultural (Medin \& Bang, 2014), and our framework was informed by the inextricable link between culture and the interpretation of science. Tibetan monastics are trained philosophers, and engagement naturally soared when topics highlighted onto-epistemological differences between Buddhism and science. Concepts were better understood when such differences were made explicit by emphasizing how scientists conceive and investigate reality. Our goal was not to integrate Buddhism and science, but to provide students with space for epistemological pluralism and structured opportunities to creatively reconcile ways of knowing individually. We appreciated learning Buddhist perspectives on 
TABLE 1 | Goals and actions in the dialogue-based learning framework.

Goals
Cultivate an inclusive learning community
Assess epistemological orientations in the classroom
Create spaces for navigating complementarities and points of friction among modes of
inquiry, without requiring group consensus

inquiry, without requiring group consensus

Provide structured opportunities for thinking across modes of inquiry

Leverage epistemological pluralism as a source of novel contributions in applied ethics

\section{Actions}

Foster a sense of belonging in the classroom (Wilson et al., 2015) and implement culturally responsive teaching (Gay, 2002)

Learn about identities and backgrounds in the classroom, acknowledge lived experiences of students (Sanger, 2020)

Use intergroup dialogue (Dessel \& Rogge, 2008) to increase awareness of other ways of knowing and use dialogue as a mode of inquiry to challenge one's own preconceived notions. Focus on mutual understanding, not consensus building

Use Writing-to-Learn (Balgopal et al., 2012) and other pedagogies that promote reflection, synthesis, and comprehension

Explore controversies from pluralist perspectives to facilitate ethical thinking (Saunders \& Rennie, 2013) topics of mutual interest, like the origin of life and the roles of attention and perception, as these exchanges heightened our awareness of onto-epistemological assumptions in science that we had not previously recognized (see Developing the DialogueBased Learning Framework Section).

Epistemological pluralism recognizes multiple, valuable ways of knowing in a collaborative context, and integration can produce innovative transdisciplinary discoveries (Miller et al., 2008). Epistemological orientation refers to diverse beliefs within and between individuals, which is contrasted with epistemic cognition as general knowledge acquisition (McGinnis, 2016). In other words, our framework focuses on acknowledging diversity in epistemological orientations among students and instructors. We use epistemological orientation as an umbrella term to encompass personal epistemology, epistemological beliefs/ postures/resources, and ways of knowing (Niessen et al., 2008).

In the classroom, considering epistemological orientations is an important component of learning (Hofer, 2001), and has implications for learning strategy use, comprehension, cognitive processing, and conceptual change (Hofer, 2008). Areas of interest include how individuals know, theories and beliefs about knowing, and how epistemology influences reasoning and learning (Hofer \& Pintrich, 1997). Epistemological orientation operationalizes philosophical frameworks to explain how students select, extract, interpret, and abstract meaning from information (Wilkinson, 1989), and can predict how students derive meaning from instruction and learning (Wilkinson \& Schwartz, 1990).

\section{DIALOGUE-BASED LEARNING AS AN INCLUSIVE PEDAGOGY}

Tibetan monastics hold positive views of science, but frequently believe that science is limited by a materialist ontology (Sonam, 2019). Many also reduced science to resultant technologies like airplanes or computers (Sonam, 2019), a phenomenon also observed among American students (Thanukos et al., 2010). To combat this trend, we explored how philosophy and science inform each other (Shraim, 2021). Leveraging epistemological pluralism created space for monastics to think like a scientist while remaining Buddhist. Monastics appreciated learning about Mendel, the 19th century monastic-scientist. Individual conceptions of who can be a scientist influences engagement (Smith and Erb 1986; Bettinger and Long 2005; Farland-Smith, 2009), positioning dialogue-based learning as an inclusive pedagogy.

We created an environment that validated and included local culture, akin to Dover's (2013) culturally responsive education. For example, we initiated conversations on mind and brain by discussing the intersection of contemplative practice and neuroscience. Likewise, we situated the scientific study of consciousness by framing questions under Buddhist theory/ practice, such as tukdam. In tukdam, an adept practitioner stays in meditation after clinical death, when brain and cardio-pulmonary functions cease, and the practitioner keeps their body intact for weeks or months beyond how science defines clinical death (Zivkovic, 2014). Tapping into existing interests, students were motivated to explore how science studies biological death, from cellular to cognitive.

\section{DIALOGUE-BASED LEARNING AS AN APPROACH TO APPLIED ETHICS}

Ethical implications are central to challenges in climate change, health, artificial intelligence, and biodiversity, and diverse ways of knowing offer novel contributions to applied ethics. Ethical reasoning provided abundant openings for deep engagement in scientific methodologies. Because ethics is foundational to Buddhism (Sodargye \& Yu, 2017; Kwah, 2020), students processed the curriculum through an ethical lens. Monastics wanted to know why scientific knowledge does not naturally motivate ethical action, for example, pointing to the lack of meaningful governmental responses to climate change. While scientists have rigorous processes for research ethics and integrity, and for handling scientific misconduct, science often benefits by drawing from other disciplines in applied ethics.

Ethics, spirituality, and medical practice are deeply intertwined in Buddhist culture, particularly in Tibetan medicine (Cameron \& Namdul, 2020). For example, in defining life, science distinguishes between living and non-living things, while Buddhism distinguishes between sentience and non-sentience 
TABLE 2 | Applying dialogue-based learning to a novel exchange between Tibetan Buddhism/Tibetan medicine and science on the COVID-19 pandemic.

\section{Prompt}

What is/are the cause(s) of the COVID-19 pandemic?

\section{Response}

Tibetan Buddhist/Tibetan Medical perspective

Primary cause: ignorance about the misconception of an independently existing self, causing attachment to oneself and greed involving wealth and sensorial pleasure. Such unwholesome acts have detrimental effects on living species and the environment, and can lead to epidemic and natural calamities. Even though there are multiple causes of the pandemic, the primary cause of the COVID-19 pandemic is a result of immoral human behavior driven by insatiable greed

\section{Science perspective}

SARS-CoV-2, the virus that causes the disease COVID-19, likely originated from a zoonotic spillover event from contact between humans and animals. Genetic analysis indicates it originated in bats, and perhaps transmitted through an intermediate animal host before infecting humans. The virus has continued to evolve into different variants since the pandemic began

What is/are the solution(s) to the COVID-19 pandemic?

\section{Tibetan Buddhist/Tibetan Medical perspective}

Prevention is the first step. Because the pandemic involves so many other problems, people need to deal with it not only through physical interventions such as medication but also by setting and cultivating positive mental attitudes toward this problem. From the Tibetan medical perspective, the focus is on strengthening the immune system and supporting impacted organ(s), reducing fever/infection, and balancing neuro-psychological problems. Along with taking care of the physical body, one's state of mind is critical

\section{Science perspective}

Public health interventions: outreach and education, masks, social distancing, medical treatments (monoclonal antibodies, medications), vaccine development and deployment, and social support programs. The One Health framework focuses on caring for human health and the health of all organisms, which, as a consequence, has positive effects on human health

How do you integrate the new way(s) of knowing with your existing one(s)?

\section{Tibetan Buddhist/Tibetan Medical perspective}

Human action causes spillover events. According to Buddhism this happens partly due to confusion about the causality between such actions and transmission of viruses from animals to humans. Due to this ignorance, people unknowingly create an atmosphere where exchange of viruses occurs between different groups of animals, including humans. Attachment to oneself and thus to wealth and sensorial pleasure also plays an important role in spreading many contagious diseases. Out of attachment to profit, people keep different animals closely together in cages at marketplaces without concern for their wellbeing. Animals suffer from getting infected from other animals, including the primary host of the virus. As a result, humans in close contact with such animals can also get infected and suffer. In Buddhism, this is only about secondary causes and cooperating conditions relating to spillover effects or how we get viruses for which our bodies are not primary hosts. Primary causes of viruses, as discussed above, are unethical human behaviors, with little to no concern for the environment and other living species

\section{Science perspective}

Biomedical science offers mechanistic explanations for how the virus was transmitted from animals to humans, and then from human to human(s). But it does not account for the causes and conditions that instigated the human-animal interaction in patient zero, or the conditions of animals in captivity. Science has generated vaccines and other medical interventions to prevent and treat illness. Scientists predict the pandemic will end when we achieve global vaccine uptake and/or reach natural herd immunity. Clinical research in mind-body health has studied many aspects of how state of mind influences health and recovery from injury and illness. But public health programs have largely not emphasized these findings, especially the role of preventative and integrative medicine. Disease has been the focus rather than improving overall global health. Investments are needed for monitoring viruses that can potentially infect humans, and for studying risk factors for future spillover events
(Balgopal et al., 2021). The Buddhist view naturally includes ethical consequences, as sentience implies the capacity to suffer and promotes non-anthropocentric solidarity with other organisms (Kwah, 2020). Buddhism is based on a moral-spiritual understanding of causality, inextricably uniting ethics and causality (Sodargye \& Yu, 2017). Axiological commitments in science (value-free) and Buddhism (value-full) mediate their respective views (Kwah, 2020), exerting broad influence on how knowledge is acquired, organized, and applied. Thus, opening the classroom to epistemological pluralism can lead to novel advances by connecting science with ethical inquiry.

\section{APPLYING THE DIALOGUE-BASED LEARNING FRAMEWORK}

Insufficiency in scientific literacy contributes to global challenges, as anti-science movements influence public discourse on 
conservation, vaccination, distribution of research funds, and climate change (Thanukos et al., 2010). When science is perceived as non-threatening to and co-existing with other ways of knowing, it creates opportunities for transdisciplinary research, which is increasingly understood as necessary for solving complex global challenges (McBean and Martinelli, 2017). We propose dialogue-based learning as a framework (Table 1) for inclusive science education and applied ethics. The first two steps work together; the instructor designs an inclusive classroom and raises awareness of epistemological orientations. Similarly, steps three and four are complementary; the instructor creates space for navigating modes of inquiry and provides structured opportunities for thinking across them. The fifth step leverages epistemological pluralism to generate novel contributions to applied ethics. In a typical STEM course, this framework can include and utilize epistemologies from other fields (e.g., social sciences, humanities) and from lived experiences (e.g., spiritual, cultural).

As an illustrative example (Table 2), we applied the framework in a dialogue, among authors, on the COVID-19 pandemic. DíazAlmeyda, a biologist, provided the science perspective, while Geshe Lhundup, a senior Tibetan monastic, provided the Buddhist perspective, and Namdul, an anthropologist and Tibetan medical doctor, provided the Tibetan medical perspective. Authors were asked to explain their views for a general audience. Then, after reviewing the other authors' explanations, each author presented an adjusted view based on what they learned in the dialogue. We present a significantly condensed summary of how authors explained the causes of and solutions to the pandemic, and how they revised perspectives at the conclusion of the dialogue. In concordance with the framework, there was no expectation to arrive at consensus or reconcile differences.

\section{DISCUSSION}

In our example dialogue, raising awareness of other modes of inquiry prompted all authors to revise their perspectives. In addressing the causes of the pandemic, the Tibetan view focused primarily on human behavior, while the science view focused on biological mechanisms. For solutions, the Tibetan view emphasized personal action and preventative medicine, while the science view relied on public health interventions and medical treatments. Interestingly, both the Tibetan and science perspectives adapted in response to the dialogue. The Tibetan view added mechanistic explanations from the science view as concrete examples to illustrate behavioral consequences. The science view reflected on the earlier emphasis on biological mechanisms and added preventative and integrative medicine as solutions.

Both perspectives borrowed ideas from the other in ways that highlighted individual strengths while expanding into new areas. It is fascinating to note that neither perspective needed to give up any central aspect of their original views. Rather, by emphasizing epistemological pluralism, the dialogue guided authors to consider other perspectives and relate new understanding with their expertise. In this way, dialogue-based learning is a pedagogical enhancement strategy, and is scalable because original course content is preserved.

Our dialogue-based learning framework was inspired by experiences teaching in ETSI. Leveraging epistemological pluralism in the classroom enhances learning by increasing diversity and inclusion, and by creating opportunities for novel contributions in applied ethics. Broader aims include increasing scientific literacy and advancing transdisciplinary research, crucial factors in solving today's global challenges. All classrooms are epistemologically plural; recognizing this in dialogue facilitates deep understanding of and respect for many ways of knowing.

\section{DATA AVAILABILITY STATEMENT}

The original contributions presented in the study are included in the article/Supplementary Material, further inquiries can be directed to the corresponding author.

\section{AUTHOR CONTRIBUTIONS}

$\mathrm{MR}, \mathrm{ED}-\mathrm{A}, \mathrm{TN}$, and $\mathrm{YL}$ contributed to the conception, development and revision of the manuscript. All authors contributed to and approved the submitted version.

\section{FUNDING}

The Emory-Tibet Science Initiative is funded by the Dalai Lama Trust, the Templeton Foundation, and Joni Winston. Namdul's time for manuscript preparation was supported by the National Institute of Health's National Center for Advancing Translational Sciences, grants TL1R002493 and UL1TR002494. The content is solely the responsibility of the author and does not necessarily represent the official views of the National Institute of the Health's National Center for Advancing Translational Sciences.

\section{ACKNOWLEDGMENTS}

We thank Geshe Lobsang Tenzin Negi for leading the EmoryTibet Science Initiative, and all the faculty, translators, and staff involved. We thank the intrepid Tibetan Buddhist monks and nuns from the many monastic institutions that have participated in ETSI. We thank the Dalai Lama, the Mind \& Life Institute, and the many scholars from many traditions for advancing the Buddhism-science dialogue and the field of contemplative science. 


\section{REFERENCES}

Balgopal, M. M., Gerardo, N. M., Topden, J., and Gyatso, K. (2021). Moving Past Postcolonial Hybrid Spaces: How Buddhist Monks Make Meaning of Biology. Sci. Educ. 105 (3), 473-497. doi:10.1002/sce.21616

Balgopal, M. M., Wallace, A. M., and Dahlberg, S. (2012). Writing to Learn Ecology: A Study of Three Populations of College Students. Environ. Educ. Res. 18 (1), 67-90. doi:10.1080/13504622.2011.576316

Bettinger, E. P., and Long, B. T. (2005). Do faculty Serve as Role Models? the Impact of Instructor Gender on Female Students. Am. Econ. Rev. 95 (2), 152-157. doi:10.1257/000282805774670149

Cameron, M., and Namdul, T. (2020). Tibetan Medicine and You: A Path to Wellbeing, Better Health, and Joy. New York: Rowman \& Littlefield.

Cho, F. (2014). Buddhism and Science in the Mirror of Language. Religions: A Scholarly J. (Hamad bin Khalifa University Press) 2014 (2). doi:10.5339/ rels.2014.science.11

Cho, F. (2012). The Limits of the Buddhist Embrace of Science. Sci. Eng. Ethics 18 (3), 539-542. doi:10.1007/s11948-012-9361-z

Desbordes, G., and Negi, L. T. (2013). A new era for Mind Studies: Training Investigators in Both Scientific and Contemplative Methods of Inquiry. Front. Hum. Neurosci. 7, 741. doi:10.3389/fnhum.2013.00741

Dessel, A., and Rogge, M. E. (2008). Evaluation of Intergroup Dialogue: A Review of the Empirical Literature. Conflict Resolution Q. 26 (2), 199-238. doi:10.1002/ crq. 230

Dover, A. G. (2013). Teaching for Social Justice: From Conceptual Frameworks to Classroom Practices. Multicultural Perspect. 15, 3-11. doi:10.1080/ 15210960.2013 .754285

Farland-Smith, D. (2009). How Does Culture Shape Students' Perceptions of Scientists? Cross-National Comparative Study of American and Chinese Elementary Students. J. Elem. Sci. Edu 21 (4), 23-42. doi:10.1007/bf03182355

Federman, A. (2011). What Buddhism Taught Cognitive Science about Self, Mind and Brain. Enrahonar 47, 39. doi:10.5565/rev/enrahonar/v47n0.162

Gay, G. (2002). Culturally Responsive Teaching in Special Education for Ethnically Diverse Students: Setting the Stage. Int. J. Qual. Stud. Educ. 15 (6), 613-629. doi:10.1080/0951839022000014349

Gray, K. M., Namgyal, D., Purcell, J., Samphel, T., Sonam, T., Tenzin, K., et al. (2020). Found in Translation: Collaborative Contemplations of Tibetan Buddhism and Western Science. Front. Commun. 4, 76. doi:10.3389/ fcomm.2019.00076

Hammerstrom, E. J. (2012). Early Twentieth-Century Buddhist Microbiology and Shifts in Chinese Buddhism's "Actual Canon". Theology Sci. 10 (1), 3-18. doi:10.1080/14746700.2012.639208

Hasenkamp, W. (2019). Fruits of the Buddhism-Science Dialogue in Contemplative Research. Curr. Opin. Psychol. 28, 126-132. doi:10.1016/ j.copsyc.2018.12.003

Hofer, B. K. (2008). "Personal Epistemology and Culture," in Knowing, Knowledge and Beliefs. Editor M. S. Khine (Dordrecht: Springer Netherlands), 3-22. doi:10.1007/978-1-4020-6596-5_1

Hofer, B. K. (2001). Personal Epistemology Research: Implications for Learning and Teaching. Educ. Psychol. Rev. 13 (4), 353-383. doi:10.1023/A: 1011965830686

Hofer, B. K., and Pintrich, P. R. (1997). The Development of Epistemological Theories: Beliefs about Knowledge and Knowing and Their Relation to Learning. Rev. Educ. Res. 67 (1), 88-140. doi:10.3102/ 00346543067001088

Hogendoorn, R. (2014). Caveat Emptor: The Dalai Lama's Proviso and the Burden of (Scientific) Proof. Religions 5 (3), 522-559. doi:10.3390/ rel5030522

Jinpa, T. (2010). Buddhism and Science: How Far Can the Dialogue Proceed? Zygon $^{\circledast} 45$ (4), 871-882. doi:10.1111/j.1467-9744.2010.01138.x

Jinpa, T., and Lama, D. (2017). Science and Philosophy in the Indian Buddhist Classics, Vol. 1: The Physical World (Issue Volume 1, the Physical World). Chennai: Wisdom Publications.

Jinpa, T., and Lama, D. (2020). Science and Philosophy in the Indian Buddhist Classics, Vol. 2: The Mind (Issue Volume 2, the Mind). Chennai: Wisdom Publications.
Kimelman, D. (2018). Ground, Path, and Fruition: Teaching Zebrafish Development to Tibetan Buddhist Monks in India. Zebrafish 15 (6), 648-651. doi:10.1089/zeb.2018.1657

Kwah, H. (2020). Bringing a Dialogue between Buddhist Multilogicality and Evolutionary Science into the Science Classroom. Cult. Stud. Sci. Educ. 15 (1), 143-155. doi:10.1007/s11422-019-09930-1

Lama, D. (2005). The Universe in a Single Atom: The Convergence of Science and Spirituality (2005-11519-000). Clay, NY, USA: Morgan Road Books.

Lopez, D. S., Jr. (2008). Buddhism \& Science: A Guide for the Perplexed. Chicago: University of Chicago Press.

McBean, G., and Martinelli, A. (2017). Blurring Disciplinary Boundaries. Science 358 (6366), 975. doi:10.1126/science.aar4320

McGinnis, D. (2016). Epistemological Orientations and Evidence Evaluation in Undergraduates. Thinking Skills and Creativity 19, 279-289. doi:10.1016/ j.tsc.2016.01.002

Medin, D. L., and Bang, M. (2014). The Cultural Side of Science Communication. Proc. Natl. Acad. Sci. 111 (Suppl. 4), 13621-13626. doi:10.1073/ pnas. 1317510111

Miller, T. R., Baird, T. D., Littlefield, C. M., Kofinas, G., Chapin, F. S., III, and Redman, C. L. (2008). Epistemological Pluralism: Reorganizing Interdisciplinary Research. E⿺S 13 (2), art46. doi:10.5751/ES-02671-130246

Mohanty, J. (1992). Reason and Tradition in Indian Thought: An Essay on the Nature of Indian Philosophical Thinking. Oxford: Oxford University Press.

Niessen, T., Abma, T., Widdershoven, G., van der Vleuten, C., and Akkerman, S. (2008). Contemporary Epistemological Research in Education. Theor. Psychol. 18 (1), 27-45. doi:10.1177/0959354307086921

Perdue, D. (2014). The Course in Buddhist Reasoning and Debate: An Asian Approach to Analytical Thinking Drawn from Indian and Tibetan Sources. First Edition. Ithaca, NY, US: Snow Lion.

Rogers, K. (2009). Tibetan Logic. Ithaca, NY, US: Snow Lion.

Samuel, G. (2014). Between Buddhism and Science, between Mind and Body. Religions 5 (3), 560-579. doi:10.3390/rel5030560

Sanger, C. S. (2020). "Inclusive Pedagogy and Universal Design Approaches for Diverse Learning Environments," in Diversity and Inclusion in Global Higher Education: Lessons from across Asia. Editors C. S. Sanger and N. W. Gleason (Berlin, Germany: Springer), 31-71. doi:10.1007/978-981-15-1628-3_2

Saunders, K. J., and Rennie, L. J. (2013). A Pedagogical Model for Ethical Inquiry into Socioscientific Issues in Science. Res. Sci. Educ. 43 (1), 253-274. doi:10.1007/s11165-011-9248-z

Sheng, C. (2017). Buddhism and Science: Some Reflections. J. Buddhist Educ. Res. 3 (2), 19-31. Retrieved from https://so06.tci-thaijo.org/index.php/jber/article/ view/243040.

Shraim, R. (2021). How Philosophy Is Making Me a Better Scientist. Nature. 23 April 2021. doi:10.1038/d41586-021-01103-x

Smith, W. S., and Erb, T. O. (1986). Effect of Women Science Career Role Models on Early Adolescents' Attitudes toward Scientists and Women in Science. J. Res. Sci. Teach. 23 (8), 667-676. doi:10.1002/tea.3660230802

Sodargye, K., and Yu, D. S. (2017). Revisioning Buddhism as a Science of the Mind in a Secularized China: A Tibetan Perspective. J. Glob. Buddhism 18, 91-111. Retrieved from https://link.gale.com/apps/doc/A528616184/AONE? $\mathrm{u}=$ anon $\sim 529 \mathrm{efb} 6 \mathrm{~d} \& \mathrm{sid}=$ googleScholar\&xid=ee543207.

Sonam, T. (2019). "Incubating Western Science Education in Tibetan Buddhist Monasteries in India," in Science Education in India: Philosophical, Historical, and Contemporary Conversations. Editors R. Koul, G. Verma, and V. NargundJoshi (Berlin, Germany: Springer), 27-45. doi:10.1007/978-981-13-9593-2_2

Thanukos, A., Scotchmoor, J. G., Caldwell, R., and Lindberg, D. R. (2010). Science 101: Building the Foundations for Real Understanding. Science 330 (6012), 1764-1765. doi:10.1126/science.1186994

Vörös, S. (2016). Buddhism and Cognitive (Neuro)Science: An Uneasy Liaison? Asian Stud. 4 (1), 61-80. doi:10.4312/as.2016.4.1.61-80

Wallingford, J. B. (2021). Aristotle, Buddhist Scripture and Embryology in Ancient Mexico: Building Inclusion by Re-thinking what Counts as the History of Developmental Biology. Development 148 (3), dev192062. doi:10.1242/ dev. 192062

Wilkinson, W. K. (1989). A Contrast of Perry and Royce: Implications for the Study of College Students' Epistemological Orientations. Can. J. Higher Educ. 19 (2), 87. doi:10.47678/cjhe.v19i2.188423 
Wilkinson, W. K., and Schwartz, N. H. (1990). Predicting Students' Epistemological Orientation from Demographic, Ability, and Learning Style Variables. Innov. High Educ. 14 (2), 131-139. doi:10.1007/BF00889614

Wilson, D., Jones, D., Bocell, F., Crawford, J., Kim, M. J., Veilleux, N., et al. (2015). Belonging and Academic Engagement Among Undergraduate STEM Students: A MultiInstitutional Study. Res. High Educ. 56 (7), 750-776. doi:10.1007/s11162-015-9367-x

Zivkovic, T. (2014). Death and Reincarnation in Tibetan Buddhism: In-Between Bodies. London \& New York: Routledge.

Conflict of Interest: The authors declare that the research was conducted in the absence of any commercial or financial relationships that could be construed as a potential conflict of interest.
Publisher's Note: All claims expressed in this article are solely those of the authors and do not necessarily represent those of their affiliated organizations, or those of the publisher, the editors and the reviewers. Any product that may be evaluated in this article, or claim that may be made by its manufacturer, is not guaranteed or endorsed by the publisher.

Copyright (c) 2021 Romano, Díaz-Almeyda, Namdul and Lhundup. This is an open-access article distributed under the terms of the Creative Commons Attribution License (CC BY).

The use, distribution or reproduction in other forums is permitted, provided the original author(s) and the copyright owner(s) are credited and that the original publication in this journal is cited, in accordance with accepted academic practice. No use, distribution or reproduction is permitted which does not comply with these terms. 